\title{
Relationship of AgNOR counts and nuclear DNA content to survival in patients with parathyroid carcinoma
}

\author{
F Lumachi, M Ermani ${ }^{1}, F_{\text {Marino }}{ }^{2}$, A Poletti $^{2}$, SMM Basso, M lacobone \\ and G Favia
}

Endocrine Surgery Unit, Department of Surgical and Gastroenterological Sciences, University of Padua,

School of Medicine, via Giustiniani 2, 35128 Padova, Italy

${ }^{1}$ Biostatistics Unit, Department of Neurosciences, University of Padua, School of Medicine, via Giustiniani 2, 35128 Padova, Italy

${ }^{2}$ Department of Pathology, University of Padua, School of Medicine, via Giustiniani 2, 35128 Padova, Italy

(Requests for offprints should be addressed to F Lumachi; Email: flumachi@unipd.it)

\begin{abstract}
The aim of this study was to evaluate the usefulness of DNA flow cytometry to determine tumor nuclear DNA index (DI), and nucleolar organizer region protein counts visualized by the argyrophil (AgNOR) technique, in confirming diagnosis and predicting clinical outcome of patients with parathyroid carcinoma (PC). We reviewed paraffin-embedded tissue sections, from 15 patients (median age 63 years, range 30-68 years) with PC who died of the disease, which were randomly compared with tissue sections from 15 age- and sex-matched patients with parathyroid adenoma (PA). The proliferative activity in parathyroid tumours as detected by DI and AgNOR counts was evaluated in all specimens. Both DI (1.37 \pm 0.33 vs $1.0 \pm 0.1)$ and AgNOR (3.01 \pm 0.31 vs $1.54 \pm 0.35)$ counts were higher $(P<0.001)$ (Student's $t$-test) in patients with $P C$ than in those with PA. Diploid $(\mathrm{DI}=1)$, aneuploid $(\mathrm{DI}>1)$ and hypoploid $(\mathrm{DI}<1)$ neoplasms were found in $11(\mathrm{PC}=4, \mathrm{PA}=7), 14(\mathrm{PC}=11$, $P A=3)$ and five $(P C=0, P A=5)$ patients respectively. The average postoperative survival in patients with PC was $46.9 \pm 37.4$ months (range 21-146 months). The survivals of patients with aneuploid $(n=11)$ and diploid $(n=4) \mathrm{PC}$ were $74.0 \pm 58.1$ and $34.1 \pm 18.4$ months $(\mathrm{P}=0.21)$ respectively. There was a significant relationship between $\mathrm{DI}$ and AgNOR counts $(\mathrm{R}=0.69, P<0.01)$, but no correlation was found between survival and both $\mathrm{DI}(\mathrm{Rho}=0.17, P=0.55)$ and AgNOR counts (Rho $=0.26$, $P=0.35)$. Moreover, there was no correlation $(P=\mathrm{NS})$ between the main preoperative biochemical parameters and survival. In conclusion, DI and AgNOR are useful in confirming the diagnosis of PC, but they are of little value in predicting the clinical outcome of patients with PC.
\end{abstract}

Endocrine-Related Cancer (2004) 11 563-569

\section{Introduction}

Primary hyperparathyroidism is a common disease. Its estimated prevalence is up to 4 per 1000 in women aged over 60 years, and its incidence is approximately 42 per 100000 (Shoback et al. 2001). In patients with primary hyperparathyroidism, abnormal parathyroid glands have been characterized as being hyperplastic, adenomatous or malignant, but parathyroid carcinoma (PC) is an uncommon finding, accounting for only $1-2 \%$ of cases (Arnaud 1994, Shane 2001, Shoback et al. 2001). The National Cancer Data Base (NCDB) reported that the mean age at diagnosis of patients with PC was 55 years (range 14-88 years), and the median tumour size was $3.3 \mathrm{~cm}$ (Hundal et al. 1999). Unfortunately, the histopathological distinction between adenomas and carcinomas, as well as between adenomas and hyperplasia, on frozen-section examination is difficult or impossible, and often no reliable signs of malignancy are detectable even on final pathology (Arnaud 1994, Shane 2001). None of the classical criteria suggested in 1973 by Shantz and Castleman are pathognomonic of PC, since several of such features may be found in parathyroid adenomas (Shantz \& Castleman 1973, 
Levin et al. 1987, Shoback et al. 2001). Thus, further histological techniques have been proposed with the aim of diagnosing malignancy and suggesting the biological behaviour of patients with PC.

The aim of this study was to evaluate the usefulness of DNA flow cytometry to determine tumour nuclear DNA index (DI), and nucleolar organizer region (NOR) protein counts visualized by the argyrophil (AgNOR) technique, in confirming diagnosis and predicting clinical outcome of patients with PC.

\section{Materials and methods}

Paraffin-wax-embedded tissue sections from 15 patients (11 men and four women, median age 63 years, range 30 68 years) with confirmed PC were randomly compared with tissue sections from 15 age- and sex-matched patients with parathyroid adenoma (PA). Overall, the 15 patients with PC had undergone 32 operations. The greatest diameter of the tumour (size) was measured by the pathologist in each patient. The histopathological characteristics of all carcinomas, according to Bondeson et al. (1993), are reported in Table 1. A low (5-25 mitoses per high-power fields $[\mathrm{HPF}])$ mitotic activity $(\times 40$ objective, $\times 10$ oculars) was found in seven cases, while five tumours showed high ( $>25$ mitoses per $50 \mathrm{HPF}$ ) mitotic activity.

Fourteen patients developed local recurrence, and the tumour caused lung metastasis in nine patients and multiple metastases (lung, bone and mediastinum) in the others. The proliferative activity in parathyroid tumours, as detected by AgNOR counts and DI, was evaluated in all specimens.

All patients died of the disease, 21-146 months (median 29 months) after the first operation.

\section{NOR silver staining and AgNOR measurement}

Sections of $3 \mu \mathrm{m}$, cut from blocks routinely processed in paraffin wax, were dewaxed in xylene and ethanol, postfixed for $30 \mathrm{~min}$ in 3:1 absolute ethanol-acetic acid solution and rehydrated (Ploton et al. 1986, Trerè et al. 1991). AgNOR staining was performed with a solution obtained by dissolving gelatine in aqueous formic acid (final concentration $2 \mathrm{~g} / \mathrm{dl}$ ) mixed with a $50 \mathrm{~g} / \mathrm{dl}$ aqueous silver nitrate solution (Ploton et al. 1986). Silver staining was done at room temperature. The numbers of AgNOR, visualized as distinct black dots, were counted by means of an image-analysis system, using a graphic monitor (Crocker \& Nar 1987). AgNOR counting was performed on 100 randomly selected nuclei of parathyroid cells, using a $\times 100$ oil-immersion objective lens (Kanematsu et al. 1997). The mean number of AgNORs per nucleus in each specimen was recorded in a database.
Table 1 Histopathological characteristics of all parathyroid carcinomas

\begin{tabular}{ll}
\hline Parameter & Cases \\
\hline Trabecular growth pattern & $12(80.0 \%)$ \\
Mitotic figures & $12(80.0 \%)$ \\
Areas of fibrosis & $11(73.3 \%)$ \\
Spindle cells & $10(66.7 \%)$ \\
Nuclear atypia & $10(66.7 \%)$ \\
Macronucleoli & $7(46.7 \%)$ \\
Pleomorphism & $6(40.0 \%)$ \\
Large nucleoli & $4(26.7 \%)$ \\
Coagulation necrosis & $5(41.7 \%)$ \\
Blood vessels invasion & $2(13.3 \%)$ \\
\hline
\end{tabular}

\section{Nuclear DNA content}

Sections of $30 \mu \mathrm{m}$ were deparaffinized as described above. As suggested by Obara et al. (1990), disaggregation was obtained by using $0.5 \%$ pepsin solution at $\mathrm{pH} 1.5$. The sample was filtered ( $40 \mu \mathrm{m}$ nylon mesh), and the single-cell nucleus suspension was resuspended in a solution containing propidium iodine and ribonuclease A. Flow cytometer measurement was used, and 20000 nuclei were read for each sample (Obara et al. 1990, Bosci et al. 1998). The DNA content was interpreted as diploid if only one G0/ G1 peak was present $(\mathrm{DI}=1.0)$, and the DI was calculated as the ratio of the peak channel number of the aneuploid G0/G1 peak to the peak channel number of the diploid G0/G1 peak (August et al. 1993).

\section{Statistical analysis}

Differences between means (that is, biochemical parameters) were tested by unpaired Student's $t$-test, while the Fisher exact test was used for fractions. The Spearman rho calculation was used to evaluate the linear relationship between age, biochemical parameters and size of the tumour and survival. The logistic regression model was used to identify factors independently predicting the clinical outcome. In the multivariate analysis, only the variables found to be significant in the univariate analysis were used.

Median survival time (MST) was calculated by the Kaplan-Meier method, while differences in MST were tested for statistical significance by the log-rank test. The differences were considered significant at a $P$ value of $<0.01$.

\section{Results}

Table 2 reports the main clinical, biochemical, and pathological data from patients with either PC or PA. In patients with $\mathrm{PC}$, the average survival was $46.9 \pm 37.4$ 


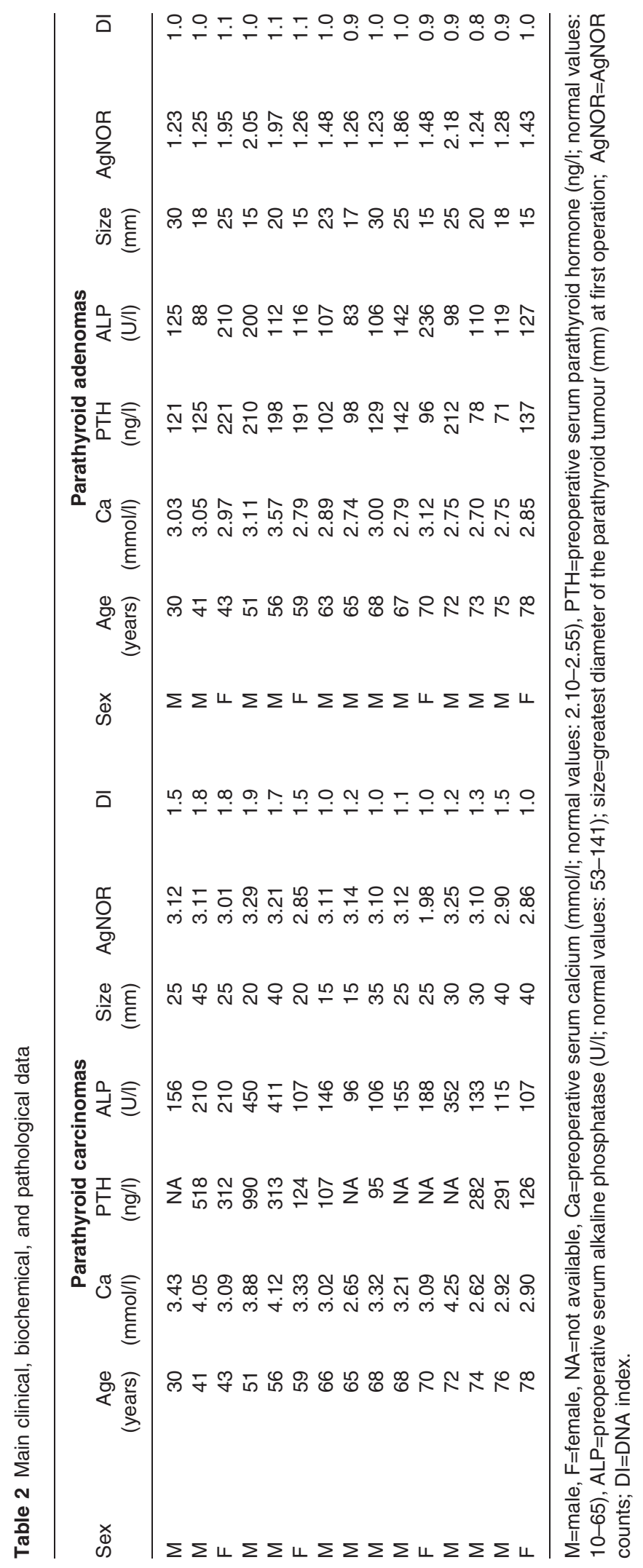




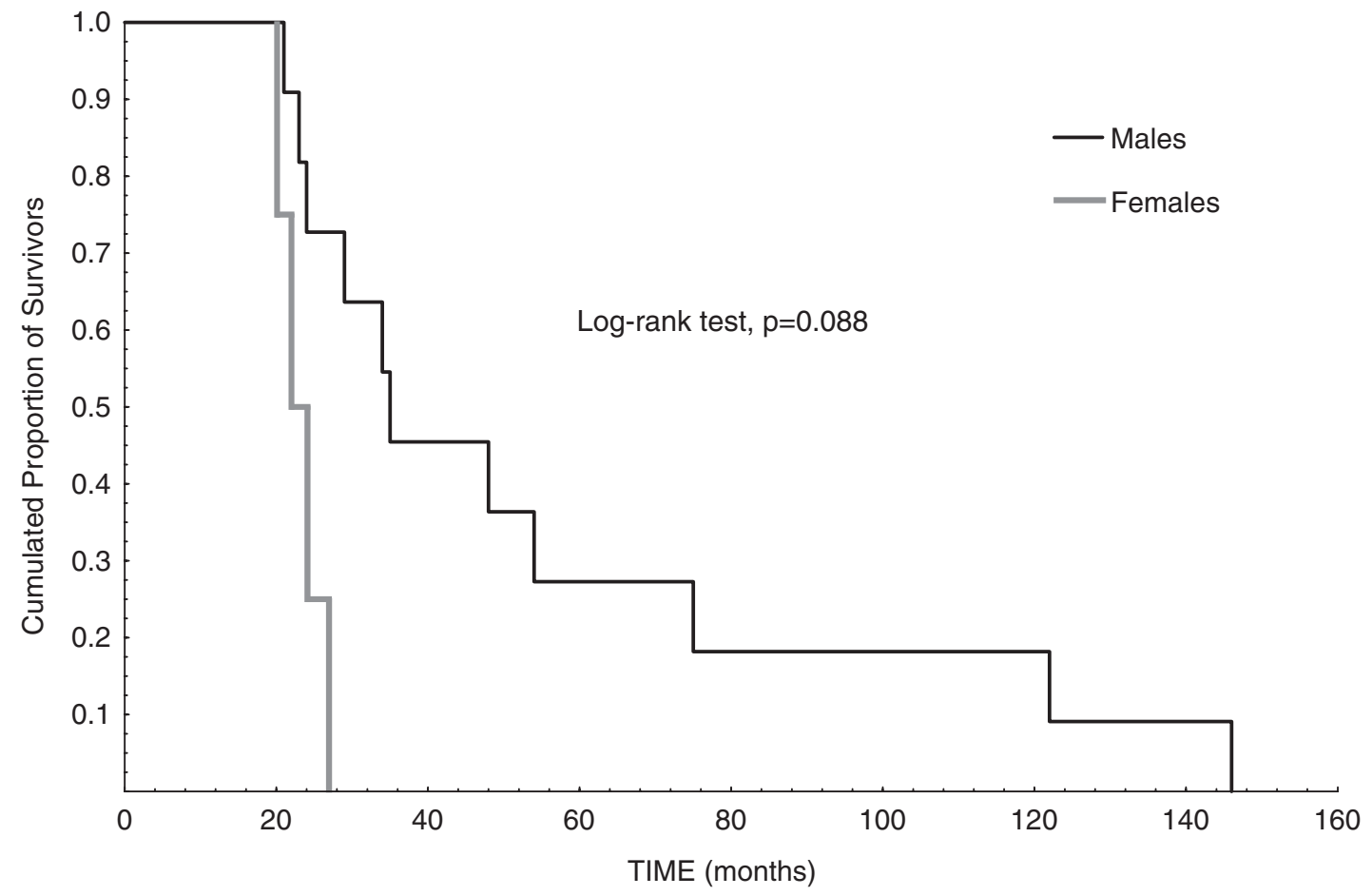

Figure 1 Cumulated proportions of survival according to the Kaplan-Meier method in male and female patients with parathyroid carcinoma.

months (range 21-146, median 29 months), and the cumulated proportions of survival, according to the Kaplan-Meier method, was different between men and women (Fig. 1), but the difference was not significant (logrank test, $P=0.09$ ).

In the univariate analysis, the mean serum calcium levels and the mean size of the removed parathyroid tumours were significantly $(P<0.01)$ higher in patients with $\mathrm{PC}$, while the mean serum alkaline phosphatase (ALP) and parathyroid hormone (PTH) levels did not differ $(P=\mathrm{NS})$ between patients with PC and those with PA (Table 3). Both AgNOR counts and DI were significantly higher $(P<0.01)$ in patients with PC. The logistic regression showed that only AgNOR was the true

Table 3 Univariate analysis between patients with parathyroid carcinomas and adenomas. Values are expressed as mean \pm standard deviation

\begin{tabular}{lccc}
\hline Parameters & Carcinomas & Adenomas & $\boldsymbol{P}$ value \\
\hline Age (years) & $60.9 \pm 14.2$ & $60.7 \pm 14.0$ & 0.97 \\
Size $(\mathrm{mm})$ & $28.7 \pm 9.5$ & $20.7 \pm 5.3$ & 0.009 \\
Ca $(\mathrm{mmol} / \mathrm{l})$ & $3.33 \pm 0.52$ & $2.94 \pm 0.22$ & 0.01 \\
PTH $(\mathrm{ng} / \mathrm{l})$ & $315.8 \pm 271.3$ & $142.1 \pm 51.4$ & 0.02 \\
ALP $(\mathrm{U} / \mathrm{l})$ & $190.5 \pm 116.3$ & $131.9 \pm 46.1$ & 0.08 \\
AgNOR counts & $3.01 \pm 0.31$ & $1.54 \pm 0.35$ & $<0.001$ \\
DNA index & $1.37 \pm 0.33$ & $1.0 \pm 0.1$ & $<0.001$ \\
\hline
\end{tabular}

independent variable, and could correctly identify 29 out of $30(96.7 \%)$ cases.

Diploid $(\mathrm{DI}=1)$, aneuploid $(\mathrm{DI}>1)$ and hypoploid $(\mathrm{DI}<1)$ tumours were found in $11(\mathrm{PC}=4, \mathrm{PA}=7$; $P=0.34), 14 \quad(\mathrm{PC}=11, \mathrm{PA}=3 ; \quad P=0.07)$, and five $(\mathrm{PC}=0, \mathrm{PA}=5 ; P=0.05)$ patients respectively.

The survivals of patients with aneuploid $(n=11)$ and diploid $(n=4)$ PC were $74.0 \pm 58.1$ and $34.1 \pm 18.4$ months $(P=0.21)$ respectively. No correlation was found between survival and the main preoperative clinical and biochemical parameters (Table 4). There was a significant relationship between DI and AgNOR counts (rho $=0.69$, $P<0.01)$, but no correlation $(P=\mathrm{NS})$ was found between survival and both AgNOR counts and DI (Fig. 2).

Table 4 Linear relationship (Spearman's rho) between survival (months) and age, main biochemical parameters, AgNOR counts and DNA index in patients with parathyroid carcinomas

\begin{tabular}{lccc}
\hline Parameter & Rho & $\mathbf{t ~ ( N - 2 )}$ & $\boldsymbol{P}$ level \\
\hline Age (years) & 0.08 & 0.28 & 0.78 \\
Size (mm) & 0.01 & 0.03 & 0.97 \\
Serum calcium (mmol/l) & 0.09 & 0.03 & 0.97 \\
PTH (ng/l) & 0.13 & 0.36 & 0.73 \\
ALP (U/l) & 0.02 & 0.06 & 0.95 \\
AgNOR counts & 0.26 & 0.97 & 0.35 \\
DNA index & 0.17 & 0.61 & 0.55 \\
\hline
\end{tabular}




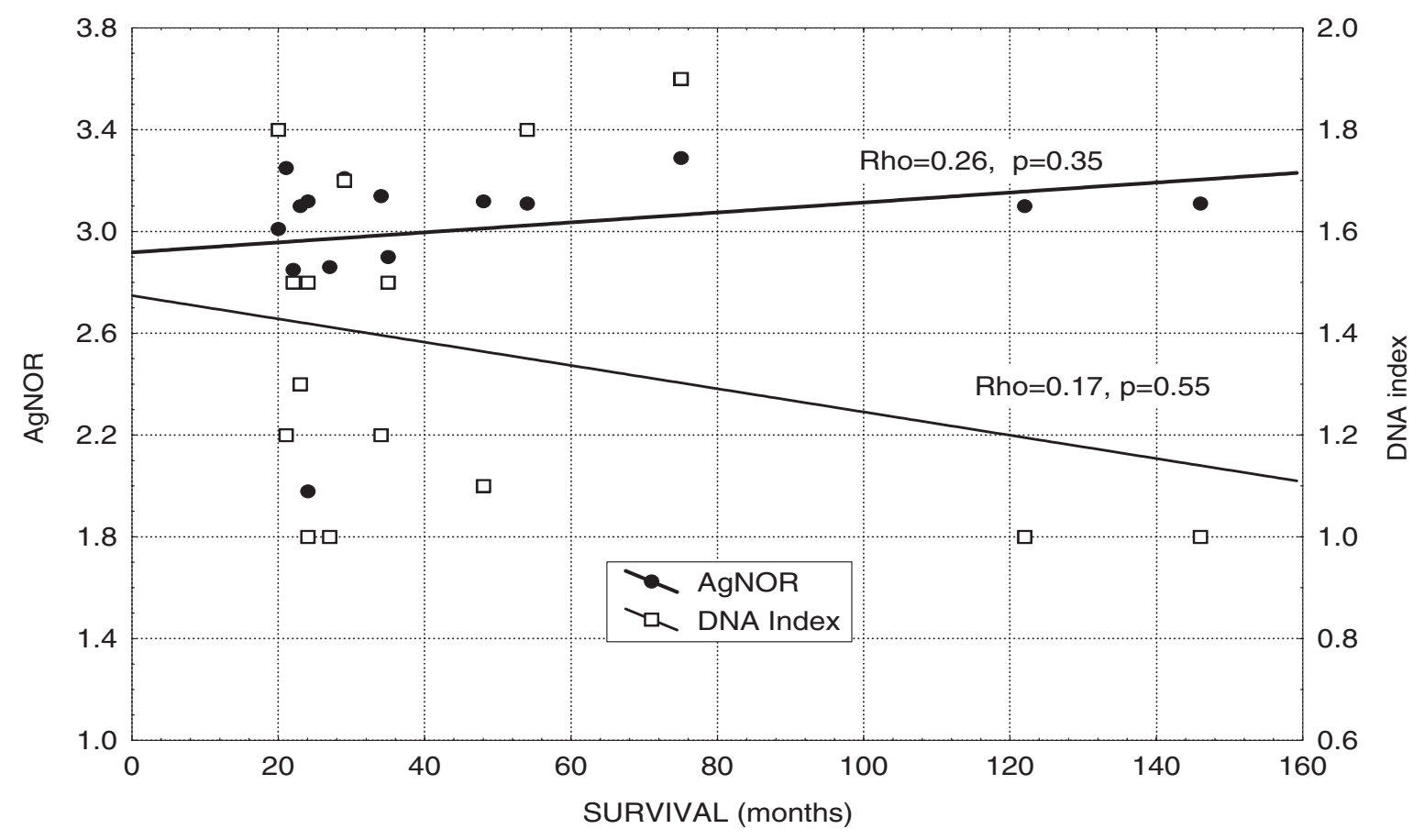

Figure 2 Relationship between survival, AgNOR counts and DNA index in patients with parathyroid carcinomas.

\section{Discussion}

PC causes $0.6-5.2 \%$ of all cases of primary hyperparathyroidism (August et al. 1993, Favia et al. 1998). The NCDB reported 286 cases of PC between 1985 and 1995 $(0.005 \%$ of the total NCBD cases), and approximately 390 cases were reported in the English literature from 1930 to 2000 (Hundhal et al. 1999, Shane 2001). The preoperative localization of such tumours is usually not difficult (Lumachi et al. 2001).

Neither tumour size nor lymph node status appear to predict survival in patients with PC, but the reported 5- and 10 -year survival rates are approximately $85 \%$ and $50 \%$ (Shane 2001). The classic pathological features are not always present in all patients with $\mathrm{PC}$, although $70 \%$ of patients may exhibit local invasion (Clayman et al. 2004). Moreover, recurrence is common, and persistent or recurrent disease may be observed at 1-20 years (Kebebew et al. 2001). Patients with PC should have lifelong followup, and different parameters should be considered to predict the biological behaviour of the tumour. Bondeson et al. (1993) showed a positive correlation between morphological variables such as fibrosis, necrosis, nuclear atypia and mitotic figures, and an aberrant DNA pattern demonstrated by image cytometry. August et al. (1993), reviewing nine patients with $\mathrm{PC}$, found that four of the five patients with evidence of tumour aneuploidy died of metastatic disease, while the four patients with diploid tumours were disease free at 1-8 years after the first operation. They concluded that DNA cytometry may help differentiate patients whose PC is likely to be indolent (diploid tumours) from those with a tumour (aneuploid) more likely to be aggressive. Unfortunately, the aneuploid DNA pattern occurs in too large a fraction of benign parathyroid lesions to be useful for differentiating between PA and PC (Mallette 1992, Obara et al. 1997). However, the DNA ploidy pattern may be a valuable prognostic factor to predict recurrence (Obara et al. 1990, 1997). We found aneuploid tumours in 11 of 15 patients with PC, and in three of 15 patients with PA. Overall, DI (mean \pm S.D.) was significantly $(P<0.01)$ higher in patients with $\mathrm{PC}$ than those with PA, but no correlation $(P=\mathrm{NS})$ was found between DI and survival.

It is difficult to determine the prognosis for patients with PC solely from the results of tumour DNA cytometry, and some studies considered the DI to be of no value in deciding the benign or malignant character of a parathyroid tumour (Obara et al. 1990, Kameyama et al. 1999). Thus, parameters other than DI were investigated, such as proliferating cell nuclear antigen (PCNA), the cell cycle-associated antigen Ki-67 and AgNOR counts. Few studies consider the usefulness of labelling indices of PCNA and Ki-67 positivity as markers of the biological behaviour of PC (Abbona et al. 1995, Kameyama et al. 2000). Kanematsu et al. (1997), studying 
25 parathyroid lesions of which three were $\mathrm{PC}$, found that the AgNOR numbers were significantly higher in PC than in PA. The authors concluded that AgNOR may be useful as an adjunct in discriminating $\mathrm{PC}$ from benign parathyroid disease. More recently, the multivariate analysis of Tuccari et al. (2000) showed that the mean area of AgNORs per cell (NORA) was unrelated to age, sex, main biochemical parameters and tumour size in a group of 10 patients with PC. A significantly higher mean NORA value was observed in patients with distant metastasis than in those with no clinical evidence of disease progression. However, surprisingly, only one patient died of disease at a mean follow-up of more than 80 months. We have not found any correlation $(P=\mathrm{NS})$ between survival and AgNOR counts in our patients.

We conclude that DI and AgNOR are useful in confirming diagnosis of PC; however, they are of little value in predicting the clinical outcome of patients with PC.

\section{Acknowledgements}

This paper was presented at the 6th European Congress of Endocrinology, Lyon (France), 26-30 April 2003. Special thanks to Dr Silvia Dall'Acqua for help in preparing the manuscript and reviewing the English.

\section{References}

Abbona GC, Papotti M, Gasparri G \& Bussolati G 1995 Proliferative activity in parathyroid tumors as detected by Ki-67 immunostaining. Human Pathology 26 135-138.

Arnaud CD 1994 The calciotropic hormones \& metabolic bone disease. In Basic and Clinical Endocrinology, pp 227-306. Eds FS Greespan \& JD Baxter. East Norwalk: Appleton \& Lange.

August DA, Flynn SD, Jones MA, Bagwell CB \& Kinder BK 1993 Parathyroid carcinoma: the relationship of nuclear DNA content to clinical outcome. Surgery 113 290-296.

Bocsi J, Perner F, Szucs J, Glaz E \& Kopper L 1998 DNA content of parathyroid tumors. Anticancer Research 18 2901-2904.

Bondeson L, Sandelin K \& Grimelius L 1993 Histopathological variables and DNA cytometry in parathyroid carcinoma. American Journal of Surgical Pathology 17 820-829.

Clayman GL, Gonzales HE, El-Nagger A \& Vassilopoulos-Sellin R 2004 Parathyroid carcinoma: evaluation and interdisciplinary management. Cancer 100 900-905.

Croker J \& Nar P 1987 Nucleolar organizer regions in lymphomas. Journal of Pathology 151 111-118.

Favia G, Lumachi F, Polistina F \& D'Amico DF 1998 Parathyroid carcinoma: sixteen new cases and suggestions for correct management. World Journal of Surgery 22 1225-1230.
Hundhal SA, Fleming ID, Fremgen AM \& Menck HR 1999 Two hundred eighty-six cases of parathyroid carcinoma treated in the U.S. between 1985-1995. Cancer 86 538-544.

Kameyama K \& Takami H 1999 DNA cytofluorimetric analysis using HP/DAPI double staining of parathyroid carcinoma arising in a patient with chronic renal failure and secondary hyperparathyroidism. Oncology Reports 6 1345-1347.

Kameyama K, Takami H, Umemura S, Osamura YR, Wada N, Sugino K, Mimura T \& Ito K 2000 PCNA and Ki-67 as prognostic markers in human parathyroid carcinomas. Annals of Surgical Oncology 7 301-305.

Kanematsu E, Matsui H, Deguchi T, Yamamoto O, Korematsu M, Kobayashi A, Nezasa SI, Yamamoto N, Takeuchi T, Tanaka T \& Kawada Y 1997 Significance of AgNOR counts for distinguishing carcinoma from adenoma and hyperplasia in parathyroid gland. Human Pathology 28 421-427.

Kebebew E, Arici C, Duh QY \& Clark OH 2001 Localization and reoperation results for persistent and recurrent parathyroid carcinoma. Archives of Surgery 136 878-885.

Levin K, Galante M \& Clark 1987 Parathyroid carcinoma versus parathyroid adenoma in patients with profound hypercalcemia. Surgery $101647-660$.

Lumachi F, Zucchetta P, Marzola MC, Boccagni P, Angelini F, Bui F, D'Amico DF \& Favia G 2000 Advantages of combined technetium-99m-sestamibi scintigraphy and high-resolution ultrasonography in parathyroid localization: comparative study in 91 patients with primary hyperparathyroidism. European Journal of Endocrinology 143 755-760.

Lumachi F, Ermani M, Basso S, Zucchetta P, Borsato N \& Favia G 2001 Localization of parathyroid tumours in the minimally invasive era: which technique should be chosen? Population based analysis of 253 patients undergoing parathyroidectomy and factors affecting parathyroid glands detection. Endocrine-Related Cancer 8 63-69.

Mallette LE 1992 DNA quantitation in the study of parathyroid lesions. A review. American Journal of Clinical Pathology $\mathbf{9 8}$ 305-311.

Obara T, Fujimoto Y, Hirayama A, Okamoto T, Hirayama A, Ito Y, Kodama T \& Ogata T 1990 Flow cytometry DNA analysis of parathyroid tumors with special reference to its diagnostic and prognostic value in parathyroid carcinoma. Cancer 65 1789-1793.

Obara T, Okamoto T, Kanbe M \& Iihara M 1997 Functioning parathyroid carcinoma: clinicopathological features and rational treatment. Seminars of Surgical Oncology 13 134-141.

Ploton D, Menager M, Jeanneson P, Himber G, Pigeon F \& Adnet JJ 1986 Improvement in the staining and in the visualization of the argyrophilic proteins of the nucleolar organizer region at the optical level. Histochemical Journal 18 5-14.

Shane E 2001 Parathyroid carcinoma. Journal of Clinical Endocrinology and Metabolism 86 485-493.

Shantz A \& Castleman B 1973 Parathyroid carcinoma: a study of 70 cases. Cancer 31 600-605.

Shoback D, Marcus R, Bikle D \& Strewler GJ 2001 Mineral metabolism \& metabolic bone disease. In Basic and Clinical Endocrinology, pp 485-493. Eds FS Greenspan \& DG Gardner. New York: McGraw-Hill. 
Trerè D, Farabegoli F, Cancelliere A, Ceccarelli C, Eusebi V \& Derenzini M 1991 AgNOR area in interphase nucleoli of human tumours correlates with the proliferative activity evaluated by bromodeoxyuridine labeling and $\mathrm{Ki}-67$ immunostaining. Journal of Pathology 165 53-59.
Tuccari G, Abbona GC, Giuffrè G, Papotti M, Gasparri G, Barresi G \& Bussolati G 2000 AgNOR quantity as a prognostic tool in hyperplastic and neoplastic parathyroid glands. Virchows Archive 437 298-303. 